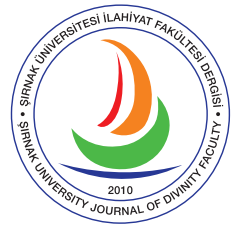

e-ISSN 2667-6575

\title{
İlahiyat Fakültesi Öğrencilerinin Mobil Öğrenmeye Yönelik Tutumları
} Attitudes of Theology Faculty Students Towards Mobile Learning

\section{Mehmet Ali Kirman}

Prof. Dr., Çukurova Üniversitesi, İlahiyat Fakültesi, Din Sosyolojisi Ana Bilim Dalı Professor, Çukurova University, Faculty of Divinity, Department of Sociology of Religion Adana, Turkey makir-man@cu.edu.tr https://orcid.org/0000-0002-3610-8190

\section{Sinan Schreglmann}

Dr. Öğr. Üyesi, Hatay Mustafa Kemal Üniversitesi, İlahiyat Fakültesi, Din Bilimleri Ana Bilim Dalı Assistant Professor, Hatay Mustafa Kemal University, Faculty of Theology, Department of Religious Sciences Hatay, Turkey sinansch@gmail.com https://orcid.org/0000-0002-5738-3167

\section{Makale Bilgisi / Article Information}

Makale Türü / Article Types: Araştırma Makalesi / Research Article

Geliş Tarihi / Received: 24 Mart / March 2020

Kabul Tarihi / Accepted: 24 Nisan / April 2020

Yayın Tarihi / Published: 15 Haziran / June 2020

Cilt / Volume: 11 Sayı / Issue: 24 Sayfa / Pages: 311-324

Atıf / Cite as: Kirman, Mehmet Ali- Schreglmann, Sinan. "İlahiyat Fakültesi Öğrencilerinin Mobil Öğrenmeye Yönelik Tutumları [Attitudes of Theology Faculty Students Towards Mobile Learning]". Şırnak Üniversitesi İlahiyat Fakültesi Dergisi Şırnak University Journal of Divinity Faculty 11/24 (June 2020), 311-324.

https://doi.org/10.35415/sirnakifd.708324

Etik Beyanı / Ethics Declaration: Bu makalede bilimsel araştırma ve yayın etiği ilkelerine riayet edilmiştir. Makale en az iki hakem tarafından incelenmiş ve intihal içermediği teyit edilmiştir./ In this article, the principles of scientific research and publication ethics are respected. It has been reviewed by at least two referees and was confirmed that it did not contain plagiarism.

Copyright (C Published by Şırnak Üniversitesi, İlahiyat Fakültesi / Şırnak, Türkiye (Şırnak University, Faculty of Divinity, Şırnak, 73000 Turkey). 


\title{
Öz
}

Bu araştırma, İlahiyat Fakültesi'nde okuyan öğrencilerin mobil öğrenme teknolojilerine yönelik tutumlarını incelemeyi amaçlanmıştır. Bu temel amaç doğrultusunda katılımcıların “Mobil Öğrenmeye Yönelik Tutum Ölçeğinden” aldıkları puanların cinsiyet/sınıf değişkenine göre anlamlı bir farklılık gösterip göstermediğine bakılmıştır. Araştırma yöntemi olarak nicel araştırma yöntemlerinden nedensel karşılaştırma tercih edilmiştir. Araştırmanın örneklemini; Hatay Mustafa Kemal Üniversitesi (MKÜ) İlahiyat Fakültesi'nde 1. Sınıfta (55) ve 2. Sınıfta (46) okuyan ve yaşları 18-30 arasında değişen toplam 101 gönüllü öğrenci oluşturmaktadır. Araştırmaya katılan öğrencilerin mobil öğrenmeye yönelik tutumlarına ait veriler nicel olarak Demir ve Akpınar tarafından 2016 yılında geliştirilen "Mobil Öğrenmeye Yönelik Tutum Ölçeği” ile toplanmıştır. Araştırmada elde edilen nicel veriler SPSS 20.0 veri analizi programı ile çözümlenmiş ve bağımsız gruplar t-testi ile analiz edilmiştir. Araştırmanın ilk sonucuna göre çalışmaya katılan İlahiyat Fakültesi öğrencilerinin cinsiyet değişkenine göre ölçek alt faktörlerinde (memnuniyet, öğrenmeye etki, motivasyon, kullanışlılık) ve ölçek toplam puanlarının anlamlı bir şekilde farklılaşmadığı sonucuna ulaşılmıştır. İkinci olarak katılımcılar arasında sınıf değişkenine göre kullanışlılık alt ölçeğinde anlamlı bir farklılık olmadığl; fakat memnuniyet, öğrenmeye etki, motivasyon ve ölçek toplam puanı açısından anlamlı bir farklılık olduğu ortaya çıkmıştır.

Anahtar Kelimeler: Din Eğitimi, Eğitim, İlahiyat, Mobil Öğrenme, Teknoloji.

\begin{abstract}
In this study, it is aimed to examine the attitudes of students studying at Hatay Mustafa Kemal University, Faculty of Theology towards mobile learning technologies. In line with this basic purpose, it was examined whether the scores the participants got from the "Attitude Scale towards Mobile Learning" differed significantly by gender / class variables. Quantitative research method was preferred as the research method. The study group of the research; A total of 101 volunteer students, aged between 18-30 and studying at the 1st grade (55) and 2nd grade (46) of the Faculty of Theology at Hatay Mustafa Kemal University (MKU). The data related to the attitudes of the students who participated in the research towards mobile learning were collected quantitatively with the "Attitude Scale towards Mobile Learning" developed by Demir and Akpınar in 2016. Quantitative data obtained in the study were analyzed with SPSS 20.0 data analysis program and independent groups were analyzed by t-test. According to the first result of the research, it was concluded that the students of the Faculty of Theology who participated in the study differed from the scale sub-factors (satisfaction, effect on learning, motivation, usefulness) and scale total scores, but this difference was not significant. Secondly, there was no significant difference in the usefulness subscale according to the class variable among the participants; but there was a significant difference in satisfaction, learning effect, motivation and scale total score.
\end{abstract}

Keywords: Religious Education, Education, Theology, Mobile Learning, Technology. 


\section{Extended Abstract}

In the historical process, human-being needed to believe in a religion in order to make sense of their lives and they wanted to teach the religion they believe to others. At this point, the need and issue of religious education emerged. People satisfied these needs at different times with different methods. In the modern world, the reality of "mobile learning" has emerged due to the scientific and technological developments. Mobile learning is a system that the lesson is taught with the support of mobile technological tools (tablet, mobile phone etc.). It makes serious contributions to the educational environment, increases the success and performance of students, and helps to develop a positive attitude towards the lesson. When it comes to mobile learning, technology should not be considered only, it should be considered as the facilitating role of learning through mobile devices without the connection of time and space, that is, "the opportunity to establish the connection between learning in and outside the classroom". Due to the coronavirus epidemic, which started at the end of 2019 but affected whole world in 2020, the fact that the distance education model is preferred at all levels of education has demonstrated the importance of mobile learning.

In this study, it is aimed to examine the attitudes of the students of the Faculty of Theology towards mobile learning technologies in the example of Faculty of Theology at Hatay Mustafa Kemal University undergraduate students. For this purpose, it was examined whether the scores obtained from the Attitude towards Mobile Learning Scale" show a significant difference according to gender and class variable. Quantitative research method was preferred as the research method. The study group of this study consists of 101 volunteer students. The data were collected quantitatively with the Attitude towards Mobile Learning Scale developed by Demir and Akpinar in 2016. The numerical data were analyzed by SPSS 20.0 and independent groups were analyzed by t-test technique.

The main assumption in this research is that although religious education is sometimes considered difficult to teach in terms of mind and emotions, it is thought that it will be learned better when it is taught with the support of materials including advanced technological tools such as mobile technologies. On the other hand, it can be said that the findings to be obtained in this research can also give an idea about the attitudes and behaviors of students of other Faculties of Theology towards mobile learning. 
According to the data obtained in the study, it was concluded that there were no significant gender-related differences in the categories of satisfaction, impact on learning, motivation, and usability which are subcategories of the Attitude Towards Mobile Learning Scale. When the total score of the scale was examined, it was seen that there was no significant difference in terms of gender. It can be said that it is seen that students of both genders adopt mobile learning courses at the same rate, mobile learning attracts their attention and the enriched course content effects on their interest in the same amount.

On the other hand, unlike the gender variable, there was differentiation in the class category except for the subscale impact on learning and usability. The mean score of the satisfaction subscale was higher and statistically significant in favor of the first grade. In other words, the first-year students are more satisfied than the second-year students that the lessons are taught through mobile learning. The same applies to motivation and the total score of scale. Interview with the lecturers who attended the course also supported this result.

In summary, it was concluded that the scores of scale sub-factors such as satisfaction, impact on learning, motivation, and usability, and scale total scores differed in terms of the gender variable of the students of the Faculty of Theology participated in the study, but this difference was not significant. There was no significant difference in usability subscale according to class variable; however, there was a significant difference in terms of satisfaction, impact on learning, motivation and total score of the scale.

Finally, when the findings of this study analyzing the students' attitudes of Faculty of Theology at Hatay Mustafa Kemal University (MKU) towards mobile learning are compared to the findings of another study on the internationalization perspective of the same Faculty students, a great similarity is observed between the findings of both studies. In other words, the views of Hatay Mustafa Kemal University Faculty of Theology students towards internationalization in higher education and their attitudes towards mobile learning are generally positive. Whether this will continue or not will depend on the attitudes of the new students of later periods. 


\section{GİRIŞ̧1}

İnsanlar gerek inanma duygusunun bir gereği olarak ve gerekse insan hayatını anlamlandırmak için her devirde mutlaka bir dine inanmışlardır. İnandıkları dinin esaslarını hem kendileri öğrenmek istemiş hem de başkalarına öğretmek istemişlerdir. ${ }^{2} \mathrm{Bu}$ noktada din eğitimi ihtiyacı ve meselesi ortaya çıkmıştır. İnsanlar din eğitimi ihtiyaçlarını çeşitli zamanlarda birbirinden farklı yöntemlerle karşılama yoluna gitmişlerdir. Modern dünyada ise yaşanan bilimsel ve teknolojik gelişmelere bağlı olarak "mobil öğrenme" gerçeği ortaya çıkmıştır.

Mobil öğrenmenin eğitim-öğretim ortamına çok ciddi katkılar sağladığı düşünülmektedir. Bu bağlamda mobil öğrenmenin eğitim ve öğretim faaliyetlerine öğrenci performansını artırırken bilişsel yükü azaltması ${ }^{3}$, derse karşı olumlu tutum geliştirilmesine yardımcı olmasi ${ }^{4}$ gibi olumlu katkıları sayılabilir. Bunlara ek olarak ders materyallerine her yerden ulaşabilme imkânı vermesi ${ }^{5}$ de zikredilebilir. Öğrenciler çoğu zaman ellerinde bulunan tablet, telefon gibi elektronik cihazlar

1 Bu makale, 23-25 Mayıs 2019 tarihlerinde düzenlenen 2. Uluslararası Akdeniz Sempozyumunda sunulan bildirinin gözden geçirilmiş ve genişletilmiş halidir./ This article is a revised and extended version of the paper which presented at the 2nd International Mediterranean Symposium organized on 23-25 May 2019.

2 Mehmet Akif Kılavuz-Hüseyin Yılmaz, "Örgün ve Yaygın Eğitimde Öğrenenlerin İhtiyaçları Doğrultusunda Din Eğitimi ve Öğretimi", Uludă̆ Üniversitesi İlahiyat Fakültesi Dergisi 18/2 (2009).

3 Yen-Ting Lin-Yi-Chun Lin, "Effects of Mental Process Integrated Nursing Training Using Mobile Device on Students' Cognitive Load, Learning Attitudes, Acceptance and Achievements", Computers in Human Behavior 55/Part B (2016).

${ }^{4}$ Florence Martin-Jeffrey Ertzberger, "Here and Now Mobile Learning: An Experimental Study on the Use of Mobile Technology", Computers \& Education 68 (2013).

5 Gimenez López vd., "Methods of Adapting Digital Content For the Learning Process via Mobile Devices", Procedia Social and Behavioral Sciences 1/1 (2009). 
ve uygun e-materyaller sayesinde, mobil ortam desteğiyle eğitim ve öğretim faaliyetlerini gerçekleştirebilir. Böylelikle; mobil ortamlar gibi bilgisayar teknolojilerinin yoğun olarak kullanıldığı öğrenme ortamlarında, bireyler çoğu bilgi ve beceriyi daha kolay bir şekilde anlamlandirmaktadır. ${ }^{6}$

Mobil öğrenme ortamları ile ilgili yapılan araştırmalara bakıldığında ${ }^{7}$, öğrencilerin tablet bilgisayar kullanımı sonucunda akademik performanslarında artış olduğunu ve tablet bilgisayar kullanımının öğrencilerin derse yönelik ilgisinin olumlu yönde arttı̆̆ı ifade edilmiştir. Elçiçek ve Bahçeci ise, öğrencilerin mevcut öğrenme ortamlarını desteklemek amacıyla geliştirdiği Mobil Öğrenme Yönetim Sistemi'nin etkisinin ve katılımcı öğrencilerin deney grubu lehine akademik başarı ve tutum gibi değişkenlerde artışa sebep olduğunu ortaya çıkarmıştır. ${ }^{8}$ Literatürde yer alan bu araştırmalar genel olarak değerlendirildiğinde mobil öğrenme ortamlarının faydaları sık sık ortaya konmuş, deneysel olarak klasik öğrenme ortamları ile karşılaştırmalar yapılmış ve son on yıl içerisinde Türkiye'de mobil öğrenme ile ilgili yapılan çalışmalar incelenmiştir. Fakat mobil öğrenme ortamları ile din eğitiminin birlikte yer aldığı bir araştırmaya literatürde maalesef rastlanılmamıştır.

Akla ve duygulara hitap etmesi bakımından öğretilmesi zaman zaman zor olarak kabul edilen din eğitimi ${ }^{9}$; mobil teknolojiler gibi ileri teknolojik araç gereçlerin kullanıldığı materyaller desteğiyle öğretildiğinde, İlahiyat Fakültesi öğrencilerinin derslerini daha kolay öğreneceğini düşündürmektedir. Dolayısıyla, bu araştırmanın temel amacı Hatay Mustafa Kemal Üniversitesi İlahiyat Fakültesi'nde okuyan öğrencilerin mobil öğrenmeye yönelik tutumlarını incelemektir. Bu temel amaç doğrultusunda katılımcıların "Mobil Öğrenmeye Yönelik Tutum Ölçeğinden" aldıkları puanların cinsiyet/sınıf değişkenine göre anlamlı bir farklılık gösterip göstermediğine bakılmıştır.

6 Rıdvan Demir, "Sanal Gerçeklik Gözlügüüne Dayalı Din Öğretimine Yönelik Öğretmen Adaylarının Tutumu", MANAS Sosyal Araştırmalar Dergisi 8/1 (2019).

7 Mehmet Yasir Poyraz, Mobil Cihazların (Tablet Pc) Eğgitim/Öğretime Etkisinin Belirlenmesi (Afyonkarahisar: Afyon Kocatepe Üniversitesi, Fen Bilimleri Enstitüsü, Yüksek Lisans Tezi, 2014).

8 Mithat Elçiçek-Ferhat Bahçeci, "Mobil Öğrenme Yönetim Sisteminin Öğrenenlerin Akademik Başarısı ve Tutumları Üzerindeki Etkilerinin İncelenmesi", Kastamonu Eğitim Dergisi 25/5 (2017).

9 Demir, "Sanal Gerçeklik Gözlüğüne Dayalı Din Öğretimine Yönelik Öğretmen Adaylarının Tutumu". 


\section{KAVRAMSAL ÇERÇEVE}

Bu başlık altında araştırmada sıklıkla kullanılan bazı kavramlarla ilgili kısa açıklamalara yer verilmiştir. Bu kavramlar şunlardır: "din", "din eğitimi" ve "mobil öğrenme".

Din, bir bireyin ya da bir topluluğun hayatını anlamlı bir bütünlük içerisinde toplayan, geçmişin ve efsanelerin, beklentilerin ve ümitlerin, ritüel ve geleneklerin toplamıdır. ${ }^{10}$ Çünkü "din" insanlara rehberlik ederken aynı zamanda bireylerin hayatına anlam katar. ${ }^{11}$ Günümüzde insan hayat1$\mathrm{n}$ anlamlandıran diğer önemli unsurlardan birinin de eğitim olduğu düşünüldüğünde ${ }^{12}$ insanlar inançlarını başkalarına eğitim kanalı ile yani "din eğitimi" ile aktarmışlardır. ${ }^{13}$ Böylelikle din eğitimi; bireysel ve sosyal bir olgu olarak eğitime konu edilmiş ve din kültürünün yetişmekte olan nesle aktarılması ve toplum bireylerinde din kişiliğinin geliştirilmesi faaliyetlerini meydana getirmiştir. ${ }^{14}$

Günümüzde en bilinen tanımıyla din eğitimi: "bireyin dini davranışlarında kendi yaşantıları yoluyla veya kasıtlı olarak istendik değişme meydana getirme süreci" olarak tanımlanmaktadır. ${ }^{15}$ Ayrıca din eğitimi "dini bilgilerin, beden, zihin ve duygu gelişimleri dikkate alınarak bireylere aktarılması ve onlarda dini bilinçlenmenin sağlatılması süreci" olarak ifade edilmiştir. ${ }^{16}$ Yani din eğitimi, dinin sosyal bir gerçeklik olarak kabul edilip dinlerin kültürlerinin yetişen nesle aktarılması ve dini kişiliğin geliştirilerek öğretime dâhil edildiği faaliyetlerdir. ${ }^{17}$

Din eğitimi "genel eğitim" içerisinde yer alır. Genel eğitim içinde yer aldığı için "din eğitimi" aslında bir eğitim görevidir. Bu görevi yerine getirebilmesi ise eğitimin genel kaideleri ve metotları ile mümkündür. ${ }^{18}$ Duyuşssal ve bilişsel öğrenme alanlarının yoğunlukta olduğu din eğitiminde, bilginin sadece hatırla-

${ }^{10}$ David A. Paillin, Groundwork of Philosophy of Religion (London: Epworth Press, 1986).

${ }^{11}$ Harvey Cox, The Seduction of the Spirit (NJ: Wildwood House, 1974); David A. Paillin, "Din Felsefesi Nedir?", çev. Ferit Uslu, Gazi Üniversitesi Çorum İlahiyat Fakültesi Dergisi 4/7-8 (2005); Mehmet Ali Kirman, Din Sosyolojisi Sözlüğü (Adana: Karahan Kitabevi, 2016), 79.

${ }^{12}$ Fahri Temizyürek-Ümran Acar, "Çizgi Filmlerdeki Subliminal Mesajların Çocuklar Üzerindeki Etkisi", Cumhuriyet International Journal of Education 3/3 (2014).

${ }^{13}$ Kılavuz-Yılmaz, “Örgün ve Yaygın Eğitimde Öğrenenlerin İhtiyaçları Doğrultusunda Din Eğitimi ve Öğretimi".

${ }^{14}$ Beyza Bilgin, Eğitim Bilimi ve Din Eğitimi (Ankara: Gün Yayıncılık, 1988).

${ }^{15}$ Cemal Tosun, Din Ĕ̆itim Bilimine Giriş (Ankara: Pegem Akademi, 2010).

${ }^{16}$ Hüseyin Yılmaz, Din Eğitimi ve Sosyal Barış (İstanbul: İnsan Yayınları, 2003), 59.

17 Abdulkadir Çekin, “Din ve Eğitimin Toplumsal Yönü Üzerine Değerlendirmeler", İnsan ve Toplum Bilimleri Araştırmaları Dergisi 2/2 (2013).

${ }^{18}$ Bayram Dalkılıç, "Bilimler Sınıflamasında Din Eğitiminin Yeri", Kuram ve Eylem Yönüyle Din Eğitiminin Teolojik ve Felsefi Temelleri, ed. Komisyon (Konya: Konya İlahiyat Derneği Yayınları, 2010). 
nacağı ve kısa süre sonra unutulacağı ezberleme işlemleri yerine, farklı teknolojik imkânların sınıf içerisinde kullanılması, öğrenci tarafından anlamlandırılan ve kalıı hale getirilen öğrenmelerin gerçekleşmesini sağlayabilir. Bunlardan en yaygın olarak bilinen ve kullanılanı mobil öğrenme ortamlarıdır.

Mobil öğrenme, giyilebilir bilgisayarlar (akıllı saat vb.), tablet bilgisayarlar, dizüstü bilgisayarlar ve özellikle akıllı cep telefonları gibi elektronik aletler vasıtasıyla yapılan öğretme ve öğrenme aktiviteleridir. ${ }^{19}$ Mobil öğrenme dendiğinde sadece teknoloji akla gelmemeli ${ }^{20}$, öğrenmenin zaman ve mekân bağı olmadan mobil cihazlar vasitasıyla kolaylaştırıcı rolü yani "sınıf içinde ve sınıf dışındaki öğrenme arasındaki bağlantıyı kurma fırsatı" düşünülmelidir. ${ }^{21}$

2019 yılı sonunda başlayan ancak 2020 yılında tüm dünyayı etkisine alan Korona virüs salgını nedeniyle eğitimin her kademesinde uzaktan eğitim modelinin tercih edilir olması mobil öğrenmenin önemini ortaya koymuştur. Uzaktan eğitim modeli ile yerel ve tekil unsurların, bir diğer ifadeyle ulusal ve uluslararası gibi kavramların önemini yitirdiği ya da küreselleşme sürecinde bilginin ve teknolojinin yaygınlaşması ile birlikte yeni ve kozmopolitan bir duruma geçilmesiyle artık bir ulusal ve uluslararası ayrımı yapmanın epistemolojik olarak mümkün olmadığı ileri sürülmüş olsa $\mathrm{da}^{22}$ henüz bu yaklaşımın bilimsel çevrelerde yaygın bir kabulü söz konusu değildir. Dolayısıyla özellikle küreselleşme çalışmalarında ulusal ve uluslararası kavramları hala kullanılmaya devam etmektedir. ${ }^{23}$

\section{YÖNTEM}

Bu araştırmada nedensel karşılaştırma modelli nicel araştırma yöntemi kullanılmıştır.

Araştırmanın örneklemini; 2018-2019 öğretim yılı Bahar döneminde Hatay Mustafa Kemal Üniversitesi İlahiyat Fakültesi 1. sinıfta (55) ve 2. sınıfta (46) okuyan, yaşları 18-30 arasında değişen (Ortalama: 20,5) ve mo-

${ }^{19}$ Mudasser F. Wyne, "Merging Mobile Learning into Traditional Education, 2013-2016", The International Conference on E-Learning in The Workplace (New York: 2015).

${ }^{20}$ Yaşar Kahraman vd., "Makine Mühendisliği Öğrencilerinin Mobil Öğrenmeye Yönelik Tutumlarının Bazı Değişkenler Açısından İncelenmesi: Sakarya Örneği", 2nd International Congress on Political, Economic and Social Studies (ICPESS), ed. Fatih Yardımcıoğlu vd. (Sakarya: Beşköprü Yayınları, 2017).

${ }^{21}$ Kadir Demir-Ercan Akpınar, "Mobil Öğrenmeye Yönelik Tutum Ölçeği Geliştirme Çalışması", Eğitim Teknolojisi Kuram ve Uygulama 6/1 (Kış 2016); Norbert Pachler vd., Mobile Learning: Structures, Agency, Practices, Gunther Kress (ed.) (Londra: Springer, 2010).

22 Beck, Ulrich. "The Cosmopolitan Condition", Theory, Culture and Society 24 (2007), 287.

${ }^{23}$ Glick-Schiller, Nina. "Beyond the Nation-State and Its Units of Analysis", Working Papers 33, Bielefeld: Center on Migration, Citizenship and Development, (2007), 5. 
bil öğrenme geçmişleri bulunan toplam 101 (46 erkek, 55 kadın) gönüllü öğrenci oluşturmaktadır.

Araştırmaya katılan öğrencilerin mobil öğrenmeye yönelik tutumları Demir ve Akpınar tarafından üniversite öğrenciler üzerinde 2016 yılında geliştirilen "Mobil Öğrenmeye Yönelik Tutum Ölçeği" ile tespit edilmiştir. Bu ölçek 4 alt kategori halinde toplam 45 sorudan oluşmuştur. Elde edilen sayısal veriler SPSS 20.0 veri analizi programı ile çözümlenmiş ve normal dağılım göstermesi dolayısıyla bağımsız gruplar t-testi tekniği ile analiz edilmiştir.

$\mathrm{Bu}$ araştırmada ana varsayım şudur: Her ne kadar din eğitimi akla ve duygulara hitap etmesi bakımından öğretilmesi zaman zaman zor olarak kabul edilse de mobil teknolojiler gibi ileri teknolojik araç gereçlerin kullanıldığı materyaller desteğiyle öğretildiğinde daha iyi öğrenileceği düşünülmektedir. Öte yandan bu araştırmada elde edilecek bulguların diğer İlahiyat Fakültesi öğrencilerinin mobil öğrenmeye yönelik tutum ve davranışları hakkında da bir fikir verebileceği söylenebilir.

\section{BULGULAR}

Araştırmanın ilk bölümünde katılımcıların Mobil Öğrenmeye Yönelik Tutum Ölçeğinden aldıkları puanların cinsiyet kategorisine göre değişip değişmediğine bakılmış ve bağımsız gruplar t-testi sonucu Tablo 1'de verilmiştir.

Tablo 1. Katılımcıların Cinsiyet Değişkeni Açısından Bağımsız Gruplar t-testi Analizi

\begin{tabular}{|c|c|c|c|c|c|}
\hline & & $\mathrm{n}$ & Ortalama & Std. Sap. & Sig. (p) \\
\hline \multirow{2}{*}{ Memnuniyet } & Erkek & 46 & 64,22 & 17,58 & \multirow{2}{*}{960} \\
\hline & Kadin & 55 & 64,38 & 14,58 & \\
\hline \multirow{2}{*}{ Öğrenmeye Etki } & Erkek & 46 & 37,28 & 8,69 & \multirow{2}{*}{,906 } \\
\hline & Kadın & 55 & 37,49 & 9,04 & \\
\hline \multirow{2}{*}{ Motivasyon } & Erkek & 46 & 23,80 & 5,61 & \multirow{2}{*}{,426 } \\
\hline & Kadın & 55 & 22,89 & 5,84 & \\
\hline \multirow{2}{*}{ Kullanışlılık } & Erkek & 46 & 22,70 & 6,40 & \multirow{2}{*}{,542 } \\
\hline & Kadın & 55 & 21,95 & 5,78 & \\
\hline \multirow{2}{*}{ Toplam } & Erkek & 46 & 148,00 & 30,21 & \multirow{2}{*}{,826 } \\
\hline & Kadın & 55 & 146,71 & 28,24 & \\
\hline
\end{tabular}


Tablo 1'e göre memnuniyet alt ölçeği ortalamaları Erkek ve Kadın için sırayla 64,22 ve 64,38 , bağımsız gruplar t-testi sonucu ise 0,05 'ten büyük $(0,960)$; öğrenmeye etki alt ölçeği ortalamaları Erkek ve Kadın için sırayla 37,28 ve 37,49 , bağımsız gruplar t-testi sonucu ise $0,05^{\prime}$ ten büyük $(0,906)$; motivasyon alt ölçeği ortalamaları Erkek ve Kadın için sirayla 23,80 ve 22,89 , bağımsız gruplar t-testi sonucu ise 0,05 'ten büyük $(0,426)$; kullanışlılık alt ölçeği ortalamaları Erkek ve Kadın için sırayla 22,70 ve 21,95, bağımsız gruplar t-testi sonucu ise $0,05^{\prime}$ ten büyük $(0,542)$; ölçek toplam puan ortalamaları Erkek ve Kadın için sırayla 148,0 ve 146,71, bağımsız gruplar t-testi sonucu ise $0,05^{\prime}$ ten büyük $(0,826)$ olduğu görülmektedir.

Araştırmanın ikinci bölümünde katılımcıların Mobil Öğrenmeye Yönelik Tutum Ölçeğinden aldıkları puanların sınıf kategorisine göre değişip değişmediğine bakılmış ve bağımsız gruplar t-testi sonucu Tablo 2'de verilmiştir.

Tablo 2. Katılımcıların Sınıf Değişkeni Açısından Bağımsız Gruplar t-testi Analizi

\begin{tabular}{|c|c|c|c|c|c|}
\hline & & $\mathrm{n}$ & Ortalama & Std. Sap. & Sig.(p) \\
\hline \multirow{2}{*}{ Memnuniyet } & 1.sinif & 55 & 67,51 & 16,44 & \multirow{2}{*}{,025 } \\
\hline & 2.sinif & 46 & 60,48 & 14,56 & \\
\hline \multirow{2}{*}{ Öğrenmeye Etki } & 1.sinif & 55 & 38,91 & 8,58 & \multirow{2}{*}{,061 } \\
\hline & 2.sinif & 46 & 35,59 & 8,90 & \\
\hline \multirow{2}{*}{ Motivasyon } & 1.sinif & 55 & 24,35 & 5,75 & \multirow{2}{*}{,045 } \\
\hline & 2.sinif & 46 & 22,07 & 5,50 & \\
\hline \multirow{2}{*}{ Kullanışlılık } & 1.sinif & 55 & 23,13 & 7,15 & \multirow{2}{*}{ 113 } \\
\hline & 2.sinif & 46 & 21,28 & 4,27 & \\
\hline \multirow{2}{*}{ Toplam } & 1.sinif & 55 & 153,89 & 29,59 & \multirow{2}{*}{,011 } \\
\hline & 2.sinif & 46 & 139,41 & 26,52 & \\
\hline
\end{tabular}

Tablo 2'ye göre memnuniyet alt ölçeği ortalamaları 1. ve 2. sınıf için sirayla 67,51 ve 60,48 , bağımsız gruplar t-testi sonucu ise 0,05 'ten küçük $(0,025)$, öğrenmeye etki alt ölçeği ortalamaları 1. ve 2 . sınıf için sırayla 38,91 ve 35,59 , bağımsız gruplar t-testi sonucu ise $0,05^{\prime}$ ten büyük $(0,061)$, motivasyon alt ölçeği ortalamaları 1 . ve 2 . sınıf için sırayla 24,35 ve 22,07 , bağımsız gruplar t-testi sonucu ise $0,05^{\prime}$ ten küçük $(0,045)$, kullanışlılık alt ölçeği ortalamaları 1 . ve 2 . sınıf için sırayla 23,13 ve 21,28 , bağımsız gruplar t-testi sonucu ise 0,05 ten büyük $(0,113)$, ölçek toplam puan ortalamaları 1 . ve 2 . sınıf için sırayla 153,89 ve 139,41 , bağımsız gruplar t-testi sonucu ise 0,05 'ten küçük $(0,011)$ olduğu görülmektedir. 


\section{SONUÇ}

Araştırmanın ilk bölümünde katılımcıların Mobil Öğrenmeye Yönelik Tutum Ölçeğinden aldıkları puanların cinsiyet kategorisine göre değişip değişmediğine bakılmış; ölçeğin alt kategorileri olan memnuniyet, öğrenmeye etki, motivasyon, kullanışlılık kategorilerinde anlamlı bir farklılaşma olmadığı sonucuna ulaşılmıştır. Aynı zamanda ölçek toplam puanına bakılmış, burada da cinsiyet söz konusu olduğunda herhangi bir anlamlı farklılaşma olmadığı görülmüştür. Bu hususta mobil öğrenmeye yönelik tutumun İlahiyat Fakültesi öğrencileri açısından farklılaşmadığı, öğrencilerin e-öğrenme gibi bir alanda eşit tutumlar sergilediklerini söylemek mümkündür. Örnek olarak öğrencilerin her iki cinsiyette de mobil öğrenme ile işlenen dersleri aynı oranda benimsediği, aynı oranda mobil öğrenme ortamlarının ilgilerini çektiği ve aynı oranda zenginleştirilmiş ders içeriklerinin derse olan ilgilerini aynı miktarda etkilediği söylenebilir.

Araştırmanın ikinci bölümünde katılımcıların Mobil Öğrenmeye Yönelik Tutum Ölçeğinden aldıkları puanların sınıf kategorisine göre değişip değişmediğine bakılmış araştırmanın ilk bölümünden farklı olarak cinsiyet söz konusunda değişim göstermeyen tutumun, sınıf kategorisinde "öğrenmeye etki" ve "kullanışlllık" alt ölçekleri haricinde değiştiği görülmüştür. Daha detaylı bakacak olursak örnek olarak memnuniyet alt ölçeğinin puan ortalaması birinci sınıf lehine daha yüksek ve istatiksel olarak anlamlı çımıştır. Yani birinci sınıf öğrencileri ikinci sınıf öğrencilerine nazaran derslerin mobil öğrenme vasıtasıyla işlenmesinden daha memnundur. Aynı durum motivasyon ve ölçek toplam puanında da geçerlidir. Bu durumun sebebi, bilimsel olarak kanitlanmasa da, Hatay Mustafa Kemal Üniversitesi İlahiyat Fakültesi'nde derse giren öğretim üyelerinin birinci sinıf derslerinde bazı dersleri mobil taşınabilir cihazlar aracilığıyla (Cep Telefonu, Tablet vs.) yapılan e-öğrenme desteği ile işlemesi, ders materyallerini (sunu, video vb.) öğrenciler ile her hafta paylaşması, yeri geldikçe video-sunu vb. gibi çoklu ortam materyallerine derslerinde de yer vermesi, aynı zamanda öğrencilerin de sürece katıldığı̆, öğrencilerden "derste sunmaları için e-materyal (sunu, video vb.) hazırlamaları ve sanal ortamda bu materyalleri paylaşmaların" istenmesi olabilir. Bu durum büyük ihtimalle bizim çalışmamızdaki mobil öğrenmeye yönelik olarak birinci sınıf öğrencilerinin tutumunu değiştirmiş olabilir. Dersin bu şekilde işlenmesiyle dersin kalitesi artmış, öğrenci her istediğinde güncel bilgiye ve ders materyallerine ulaşmış, öğrenmeler kolaylaşmış, derse ilişkin motivasyon ve sosyal etkileşim artmış, mobil cihazlar aracılığıyla öğrencilerin ödevlerini daha kolay yapmış olması söz konusu olabilir. 
Hatay Mustafa Kemal Üniversitesi (MKÜ) İlahiyat Fakültesi öğrencilerinin mobil öğrenmeye yönelik tutumlarının analiz edildiği bu araştırmadan elde edilen bulgular ile aynı Fakülte öğrencilerinin uluslararasılaşma bakışına dair yapılmış olan araştırmanın ${ }^{24}$ bulgularıyla karşılaştırıldığında büyük oranda bir yakınlık arz ettiği görülmektedir. Bir diğer ifadeyle Hatay Mustafa Kemal Üniversitesi İlahiyat Fakültesi öğrencilerinin gerek yükseköğretimde uluslararasılaşmaya bakışları ve gerekse mobil öğrenmeye yönelik tutumları genelde olumlu yöndedir. Ancak bu çizginin devam edip etmeyeceği daha sonraki dönemlerin öğrencilerinin tutumuna bağlı olacaktır.

${ }^{24}$ Dölek, İlbey - Taşçı, Gülşah. “Hatay Mustafa Kemal Üniversitesi İlahiyat Fakültesi'nin Uluslararasılaşma Açısından Değerlendirilmesi", Antakiyat 1/2 (2018), 157-178. 


\section{KAYNAKÇA}

Beck, Ulrich. "The Cosmopolitan Condition", Theory, Culture E Society, 24 (2007), 286-290.

Bilgin, Beyza. Eğitim Bilimi ve Din Eğitimi. Ankara: Gün Yayıncılık, 1988.

Cox, Harvey. The Seduction of the Spirit. NJ: Wildwood House, 1974.

Çekin, Abdulkadir. “Din ve Eğitimin Toplumsal Yönü Üzerine Değerlendirmeler”. İnsan ve Toplum Bilimleri Araştırmaları Dergisi 2/2 (2013), 36-48.

Dalkılıç, Bayram. "Bilimler Sınıflamasında Din Eğitiminin Yeri". Kuram ve Eylem Yönüyle Din Eğitiminin Teolojik ve Felsefi Temelleri. ed. Komisyon. 72-83. Konya: Konya İlahiyat Derneği Yayınları, 2010.

Demir, Kadir-Akpınar, Ercan. “Mobil Öğrenmeye Yönelik Tutum Ölçeği Geliştirme Çalışması”. Ĕ̆itim Teknolojisi Kuram ve Uygulama 6/1 (Kış 2016), 59-79.

Demir, Rıdvan. “Sanal Gerçeklik Gözlügüne Dayalı Din Öğretimine Yönelik Öğretmen Adaylarının Tutumu". MANAS Sosyal Araştırmalar Dergisi 8/1 (2019), 847-861.

Dölek, İlbey - Taşçı, Gülşah. "Hatay Mustafa Kemal Üniversitesi İlahiyat Fakültesi'nin Uluslararasılaşma Açısından Değerlendirilmesi". Antakiyat 1/2 (2018), 157-178.

Elçiçek, Mithat-Bahçeci, Ferhat. “Mobil Öğrenme Yönetim Sisteminin Öğrenenlerin Akademik Başarısı ve Tutumları Üzerindeki Etkilerinin İncelenmesi". Kastamonu Ĕ̆itim Dergisi 25/5 (2017), 1695-1714.

Glick-Schiller, Nina. "Beyond the Nation-State and Its Units of Analysis", Working Papers 33, Bielefeld: Center on Migration, Citizenship and Development, (2007).

Kahraman, Yaşar, Bağc1, Hakkı - Aslan Bağc1, Özlem. “Makine Mühendisliği Öğrencilerinin Mobil Öğrenmeye Yönelik Tutumlarının Bazı Değişkenler Açısindan İncelenmesi: Sakarya Örneği". 2nd International Congress on Political, Economic and Social Studies (ICPESS). ed. Fatih Yardımcıŏlu vd. 3/462-472. Sakarya: Beşköprü Yayınları, 2017.

Kılavuz, Mehmet Akif - Yılmaz, Hüseyin. “Örgün ve Yaygın Eğitimde Öğrenenlerin İhtiyaçları Doğrultusunda Din Eğitimi ve Öğretimi”. Uludă̆ Üniversitesi Illahiyat Fakültesi Dergisi 18/2 (2009), 123-139.

Kirman, Mehmet Ali. Din Sosyolojisi Sözlüğ̈̈̈. Adana: Karahan Kitabevi, 2016.

Kirman, Mehmet Ali - Demir, Rıdvan. "İlahiyat Fakültesi Öğrencilerinin Beklenti ve Sorunları: Mustafa Kemal Üniversitesi Örneği”. Antakiyat 1/1 (2018), 1-21.

Lin, Yen-Ting-Lin, Yi-Chun. “Effects of Mental Process Integrated Nursing Trai- 
ning Using Mobile Device on Students' Cognitive Load, Learning Attitudes, Acceptance and Achievements". Computers in Human Behavior 55/Part B (2016), 1213-1221.

López, Gimenez, Royo, T. Magal, Laborda, Jesus García-Calvo, F. Garde. “Methods of Adapting Digital Content For the Learning Process via Mobile Devices". Procedia Social and Behavioral Sciences 1/1 (2009), 2673-2677.

Martin, Florence-Ertzberger, Jeffrey. "Here and Now Mobile Learning: An Experimental Study on the Use of Mobile Technology". Computers \& Education 68/ (2013), 76-85. http://doi.org/10.1016/j.compedu.2013.04.021

Pachler, Norbert, Bachmair, Ben-Cook, John. Mobile Learning: Structures, Agency, Practices. ed. Gunther Kress, Londra: Springer, 2010.

Paillin, David A. Groundwork of Philosophy of Religion. London: Epworth Press, 1986.

Paillin, David A. “Din Felsefesi Nedir?”. çev. Ferit Uslu. Gazi Üniversitesi Çorum İlahiyat Fakültesi Dergisi 4/7-8 (2005), 121-154.

Poyraz, Mehmet Yasir. Mobil Cihazlarm (Tablet Pc) Ĕgitim/Öğretime Etkisinin Belirlenmesi. Afyonkarahisar: Afyon Kocatepe Üniversitesi, Fen Bilimleri Enstitüsü, Yüksek Lisans Tezi, 2014.

Temizyürek, Fahri-Acar, Ümran. "Çizgi Filmlerdeki Subliminal Mesajların Çocuklar Üzerindeki Etkisi”. Cumhuriyet International Journal of Education- 3/3 (2014), 25-39.

Tosun, Cemal. Din Ĕğitim Bilimine Giriş. Ankara: Pegem Akademi, 4. Basım, 2010.

Wyne, Mudasser F. "Merging Mobile Learning into Traditional Education, 2013-2016". The International Conference on E-Learning in The Workplace. New York: 2015.

Yılmaz, Hüseyin. Din Ĕ̆itimi ve Sosyal Barış. İstanbul: İnsan Yayınları, 2003. 